\title{
Meta-Heuristic Firefly Algorithm Based Optimal Design of Passive Harmonic Filter for Harmonic Mitigation
}

\section{Dr.A.S.S.Murugan}

Associate Professor, Department of Electrical and Electronics Engineering, CVR College of Engineering, Mangalpalli, RR District, Telangana, India

assm17174@gmail.com

\begin{abstract}
In present years, the increasing use of power electronic based nonlinear devices in various power system applications causes harmonic distortions in source side voltages and currents. The unwanted harmonic distortion can introduce detrimental effects on electrical equipment and temperature increases in neutral conductors and distribution transformers. In this paper, a new optimization method of Meta-heuristic firefly algorithm is proposed for the optimal design of passive harmonic filters to mitigate the harmonics existing in the power system environment. The performance of the proposed firefly algorithm based passive filter evidences better result compared with the other algorithm based methods.
\end{abstract}

Keywords: Harmonics, THD, Firefly Algorithm, Nonlinear loads, Point of Common Coupling

\section{Introduction}

Harmonic distortions are one of the important power quality issues. Due to the widespread use of non-linear devices, significant amount of harmonics present in power system. When distorted harmonic currents interact with the impedance of the circuit, voltage also highly distorted at the point of common coupling (PCC). The following problems may incurred due to distorted current and voltage such as overheating of electrical equipments, false tripping of protection devices and overheating of capacitors for power factor correction. However, harmonic mitigation schemes are necessary to be considered for maintaining good quality and reliable power supply. IEEE Standard 519-1992 or IEEE 5192014 (1993, 2014) [1-2] recommends a guideline to limit and mitigate the harmonics present in power system. Harmonic filters such as Active filters, passive filters, and hybrid filters are recommended to reduce the harmonics within the limits as per the guidelines of IEEE standards. Active harmonic filter is one of the main filter techniques which consist of active components to absorb harmful harmonics in power system. The drawbacks of active filters are more complex and expensive method compared with other methods (Subjak, Mcquilkin1990 \& Bose1992) [3-4]. Passive harmonic filters are widely used for harmonic minimization studies because of the following advantages such as simple construction, easy to install, lower cost and less maintenance (Kazemi-Robati, Sepasian, 2019)[5]. In general, the passive harmonic filter provides better performance characteristics which divert the unwanted harmonic currents near its tuned frequency. Further, the harmonic distortions in voltage also reduced. In general, the conventional design technique for passive harmonic filter is a simple trial and error method but it has certain problems as they do not provide optimal results in several occasions. Nowadays, many optimization algorithms are developed for optimal selection of harmonic filter parameters.A swarm-based Improved Artificial Bee Colony (ABC) algorithm is proposed to design passive harmonic filter parameters (Bose,Biswas, Vasilakos,Laha 2014)[6]. (Murugan, Rajaram and Renukadevi 2016)[7] proposed a harmonic suppression method 


\section{www.rspsciencehub.com}

by installation of Dragonfly Algorithm (DA) based passive harmonic filter in the circuit. A solution technology based on an optimization method of Genetic Algorithm (GA) is applied to determine the filter parameters (Maheswaran, Rajasekar, Ashok Kumar 2014\&Yaow-Ming Chen 2003)[89]. Many other design techniques (Yang 2018) [10] such as simulated annealing, genetic algorithms and differential evolution methods are complex methods but have problems in convergence. In this work, particle swarm optimization algorithm and firefly algorithm are used to design the optimal parameters of passive filter. The numerical results in the table shows that the comparison between PSO and firefly algorithm and also indicates that the superiority of the algorithm for the design of harmonic filter. The remaining sections of this paper are well structured as follows. Section II briefs the basics of proposed algorithms of FA and PSO for the filter parameter selection. Section III indicates the performance characteristics of LC passive filter and thesimulation results.A conclusion of the work is presented in section IV.

\section{Proposed Algorithm}

\subsection{Particle Swarm Optimization}

Particle swarm optimization (PSO) is an efficient and faster metaheuristic algorithm first recommended by Kennedy and Eberhart in 1995 (Kennedy and Eberhart 1995) [11]. PSO algorithm is a self-correctedpopulation-oriented optimization method which is motivated by the movement of organisms such as bird flocking and fish schooling. An individual in a swarm also called a particle looking for optimal position in the problem search area and each particle fine-tunes its position from its present velocity, previous knowledge and the experience gathered by the adjacent particles. Thus the particle swarm algorithm can be used to solve complicated problems. PSO algorithm is designed with anassembly of random particles (solutions) and then examines for targets by modernizing generations. For each and every computation count, each particle is updated with two "best" fitness solutions. The mainand first one is the best fitness solution and also that fitness value is stored. This best fitness solution value is named as $p_{\text {best }}$ and another "best" assessment is identified which also attained by aparticle element in the population. One best fitness solution is named as global best ( $\mathrm{g}_{\text {best }}$ )
Volume 03 Issue 01 January 2021

and another finest fitness solution is a local best $\left(l_{\text {best }}\right)$. In a PSO algorithm, the following equations are considered for updating of every particle's significant characters such as velocity and position in the search space. Hence the movements of particle through a search space can be measured.

$$
\begin{aligned}
& \mathrm{V}_{\mathrm{id}}(\mathrm{m}+1)=\mathrm{w} \times \mathrm{V}_{\mathrm{id}}(\mathrm{m})+\mathrm{c}_{1} \times \operatorname{ran}_{1}\left(\mathrm{p}_{\mathrm{id}}(\mathrm{m})-\right. \\
& \left.\mathrm{X}_{\mathrm{id}}(\mathrm{m})\right)+\mathrm{c}_{2} \times \operatorname{ran}_{2}\left(\mathrm{p}_{\mathrm{gd}}(\mathrm{m})-\mathrm{X}_{\mathrm{id}}(\mathrm{m})\right) \\
& \mathrm{X}_{\mathrm{id}}(\mathrm{m}+1)=\mathrm{X}_{\mathrm{id}}(\mathrm{k})+\mathrm{V}_{\mathrm{id}}(\mathrm{k})
\end{aligned}
$$

where,

- $m$ denotes the $\mathrm{i}^{\text {th }}$ iteration

- $w$ is the inertia weight

- $X_{\text {id }}$ represents particle position

- $\mathrm{V}_{\text {id }}$ represents particle velocity

- $p_{\text {id }}$ represents best position

- $\mathrm{c}_{1}, \mathrm{c}_{2}$ represents cognitive and social parameters,

- $\operatorname{ran}_{1}, \operatorname{ran}_{2}$ are random values between numbers 0 and 1

\subsection{Firefly Algorithm}

Nature inspired Firefly Algorithm (FA) is a meta-heuristic optimization algorithm was first proposed by Xin-She Yang [10] in the year 2007 which is stimulated by the behaviour and light flashing arrangement of fireflies. The flashing light isformed by the chemical process taken inside of the bodies of fire flies which is termed bioluminescene and produced from the lower abdomen. Generally, the fireflies use the behaviour of flash light for signal system to invite mates or prey and also this behaviour used for protectingfrom predators.

In general, firefly algorithm is used in numerousarea of optimization problems for determining the optimal result to make something promising minimizing or maximizing the applications, firefly algorithm is used to solve economic dispatch problems (Apostolopoulos and Vlachos 2011) [12].

The formulation of flashing light is associated with the objective function of the problem. There are two important disputes are considered in firefly algorithm that are the changing of light concentration and provision of attraction. The light concentration of fireflies I(r) is changed according to the Inverse Square law which is denoted (Johari, Zain, Mustaffa and Udin 2013) [13] as

$I(r)=\frac{I_{s}}{r^{2}}$ 
www.rspsciencehub.com

For a specified medium, the intensity of light I is well-defined with the distance $r$ and another term named as stable light absorption coefficient $(\gamma)$,

$$
I=I_{0} e^{-\gamma r^{2}}
$$

where

- $\mathrm{I}_{\mathrm{S}}$ represents the intensity of light at the source.

- $\mathrm{I}_{0}$ indicates the actual intensity of light.

The attractiveness or brightness of the firefly is proportional to the light intensity between neighbouring fireflies and the changing of attractiveness $\beta$ is defined with the distance between fireflies $(\mathrm{r})$ by

$\beta=\beta_{0} e^{-r^{2}}$

Where $\beta_{0}$ denotes the brightness constant at distance $r=0$. The distance $\left(r_{i j}\right)$ traced between any two fireflies of $i$ and $j$ are residence at $x_{i}$ and $x_{j}$. These are represented as a Cartesian or Euclidean distance using the equation (4)

$r_{i j}=\sqrt{\sum_{t=1}^{d}\left(x_{i, t}-x_{j, t}\right)^{2}}$

The following key equation is utilized to determine the position of the particle $\mathrm{x}_{\mathrm{i}}$

$x_{i}^{t+1}=x_{i}^{t}+\beta_{0} e^{-\gamma r^{2} i j}\left(x_{j}^{t}-x_{i}^{t}\right)+\alpha \varepsilon_{i}^{t}$

\section{Results and Discussion}

\subsection{Proposed System}

Figure 1 indicates the simulation model of the proposed test system. The test circuit comprises of a three-phase 400 volt, $50 \mathrm{~Hz}$ Supply system with nonlinear load of rectifier circuit

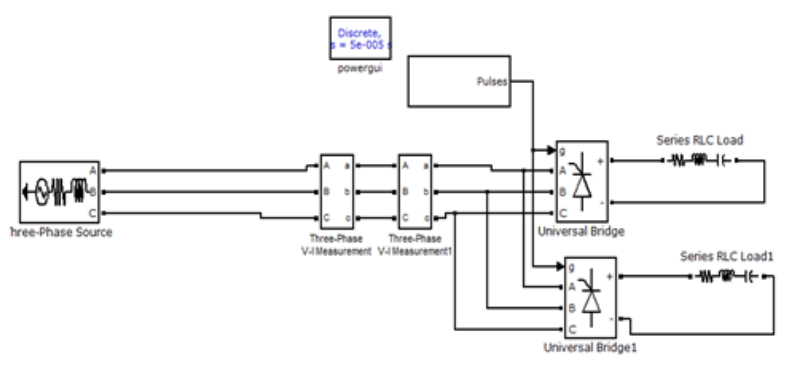

\section{Fig.1 Simulink model of the proposed test system}

\subsection{Current waveform without Filter}

The performance of the proposed test circuit is simulated as shown in Fig.1. The current and voltage are measured at Point of Common
Volume 03 Issue 01 January 2021

Coupling (PCC).During the analysis, it is observed thatthe $5^{\text {th }}$ order harmonics is dominated in all the three phases $\mathrm{A}, \mathrm{B}$ and $\mathrm{C}$ and also noted that the current harmonic distortion $\left(\mathrm{THD}_{\mathrm{I}}\right)$ in three phases of $\mathrm{A}, \mathrm{B}$ and $\mathrm{C}$ respectively are $13.34 \%, 14.96 \%$ and $16.40 \%$.

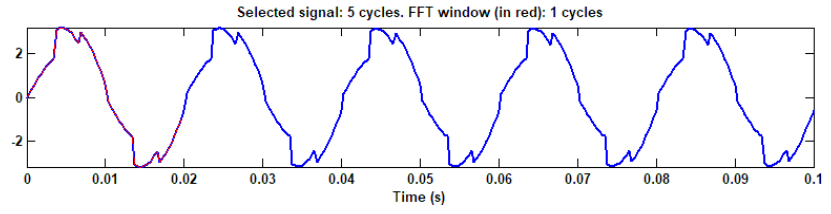

Fig. 2(a) Current waveform without Filter

It is to be noted that, the obtained $\mathrm{THD}_{\mathrm{I}}$ values are not satisfied the harmonic limit specifications of IEEE 519-1992 harmonic standard. These higher amounts of harmonic distortions will increase power quality issues in the system.

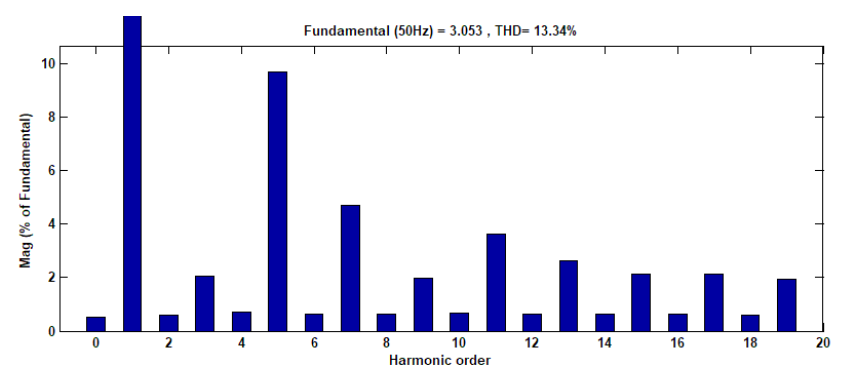

Fig.2(b) FFT analysis of current waveform without Filter

Figure 2(a) shows the input current waveform without passive filter.Figure 2(b) shows the FFT spectrum analysis of input current waveform without passive harmonic filter.

\subsection{Current waveform with filter}

The passive harmonic filter circuit is designed to reduce the current harmonics using the conventional manual calculation method. The measured $\mathrm{THD}_{\mathrm{I}}$ value is $11.23 \%$ in phase A. Figure 3(a) shows the input current waveform with passive filter by conventional method.Figure 3(b) shows the FFT analysis of the input current waveform with passive harmonic filter by conventional method.

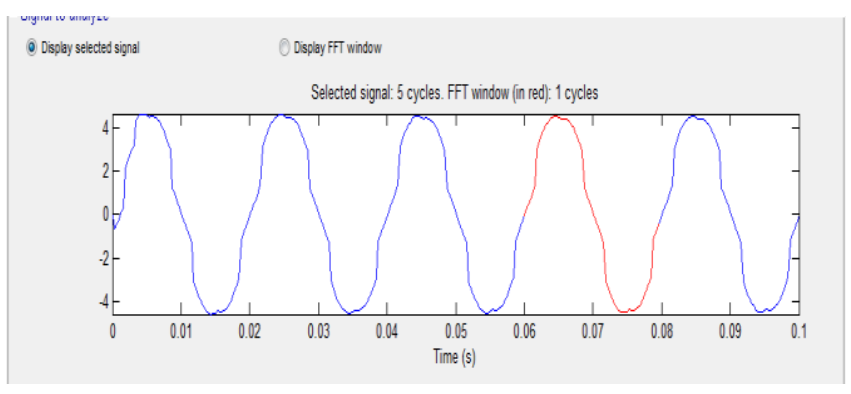

Fig. 3(a) Current waveform with passive filter by manual calculation 


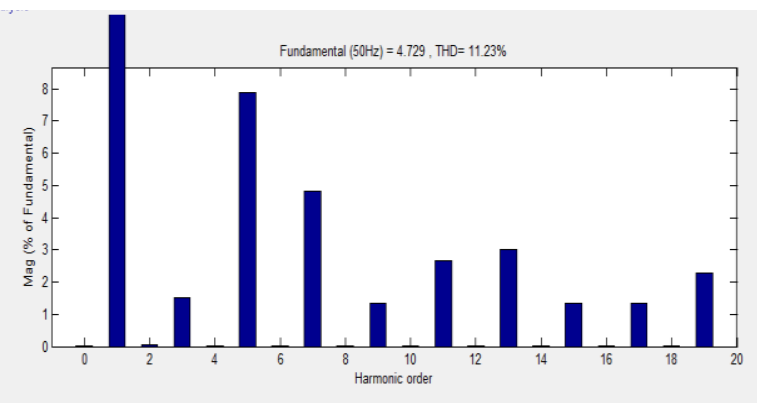

Fig.3(b) FFT Analysis of Current Waveform with passive filter by manual calculation

The passive harmonic filter circuit is designed to reduce the current harmonics using the PSO algorithm. The measured $\mathrm{THD}_{\mathrm{I}}$ value is $9.89 \%$ in phase A. Figure 4(a) shows the input current waveform with passive filter by using the PSO algorithm. Figure 4(b) shows the FFT analysis of the input current waveform with passive filter by using the PSO algorithm.

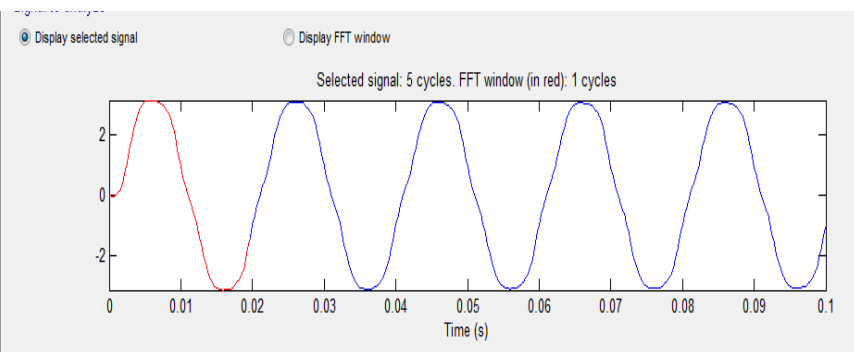

Fig. 4(a) Current waveform with passive filter by PSO algorithm

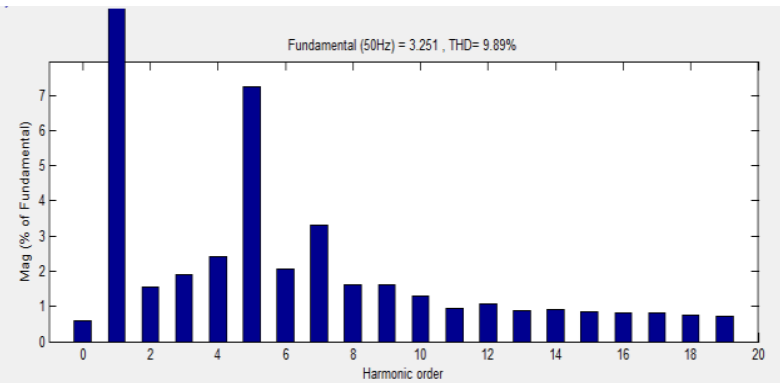

Fig. 4(b) FFT Analysis of Current Waveform with passive filter by PSO algorithm

The performance of the firefly algorithm based passive filter is verified with the help of a test simulation circuit. The current and voltage are measured at PCC. The total harmonic distortion value of current is 4.72 measured at PCC. It is to be noted that the obtained $\mathrm{THD}_{\mathrm{I}}$ values are satisfied with the specifications of IEEE 519-1992 standard.

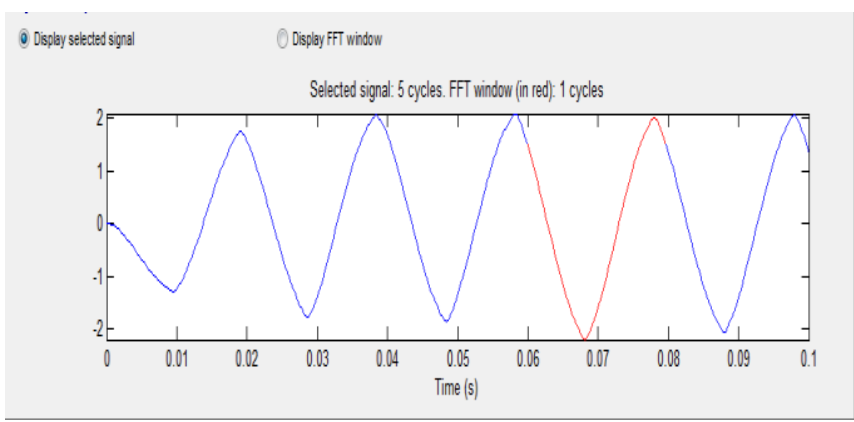

Fig.5(a) Current waveform with passive filter by Firefly algorithm

Figure 5(a) indicates the input current waveform with passive filter by using the FFA algorithm. Figure 5(b) indicates the FFT spectrum analysis of the input current waveform with passive filter by using the FFA algorithm.

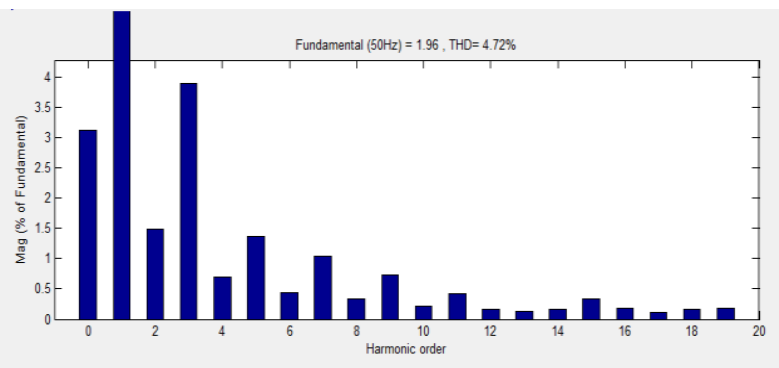

Fig.5(b) FFT Analysis of Current Waveform with passive filter by Firefly algorithm.

Table 1 presents the comparison of simulated results of $\mathrm{L}$ and $\mathrm{C}$ values for different passive filter circuits for phases $\mathrm{A}, \mathrm{B}$ and $\mathrm{C}$.

Table.1. Determination of $L \&$ C Values

\begin{tabular}{|c|c|c|c|c|}
\hline \multicolumn{2}{|c|}{} & $\begin{array}{c}\text { Manual } \\
\text { Calculation }\end{array}$ & PSO & Firefly \\
\hline \multirow{2}{*}{$\begin{array}{c}\text { PHASE } \\
\text { A }\end{array}$} & $\begin{array}{c}\text { L1 } \\
(\mathrm{mH})\end{array}$ & 0.0740 & 0.4500 & 2.0975 \\
\cline { 2 - 5 } & $\begin{array}{c}\mathrm{C} 1 \\
(\mathrm{~F})\end{array}$ & 0.0015 & 0.060 & 2.4297 \\
\hline $\begin{array}{c}\text { PHASE } \\
\text { B }\end{array}$ & $\begin{array}{c}\text { L2 } \\
(\mathrm{mH})\end{array}$ & 0.0614 & 0.2875 & 2.1965 \\
\cline { 2 - 5 } & $\mathrm{C} 2(\mathrm{~F})$ & 0.00017 & 0.00055 & 2.3347 \\
\hline \multirow{2}{*}{$\begin{array}{c}\text { PHASE } \\
\text { C }\end{array}$} & $\begin{array}{c}\text { L3 } \\
(\mathrm{mH})\end{array}$ & 0.0854 & 0.3300 & 2.0888 \\
\cline { 2 - 5 } & $\mathrm{C} 3(\mathrm{~F})$ & 0.00013 & 0.0075 & 2.6376 \\
\hline
\end{tabular}

Table 2 shows the comparison of THD values for different passive filter circuits in phase A. 
www.rspsciencehub.com

Table.2. THD values measured in Phase A with different methods

\begin{tabular}{|l|l|l|}
\hline \multicolumn{2}{|l|}{ Without Filter THD } & $13.34 \%$ \\
\hline \multirow{2}{*}{$\begin{array}{l}\text { With Passive } \\
\text { FilterTHD } \\
\text { Value }\end{array}$} & $\begin{array}{l}\text { Manual } \\
\text { calculation }\end{array}$ & $11.23 \%$ \\
\cline { 2 - 3 } & PSO Algorithm & $9.89 \%$ \\
\cline { 2 - 3 } & $\begin{array}{l}\text { FIREFLY } \\
\text { Algorithm }\end{array}$ & $4.72 \%$ \\
\hline
\end{tabular}

\section{Conclusion}

Harmonics pollution in the power system is increases due to the increasing usage of power electronic controlled loads. Due to the large usage of nonlinear loads causes the power quality problems arises in the power system. Therefore, harmonic elimination is essential to improve the quality of the supply. In this work, harmonics is mitigated with the help of a passive filter, whose design is based on PSO and Firefly technique. It is observed that Firefly technique helps in efficient reduction of power system harmonics. Firefly is found to be very much efficient and superior to PSO method of filter design in harmonic mitigation. The Fire fly algorithm based passive filter results show that the satisfactory performance of the filter designed by using other methods.

\section{References}

[1] IEEE Recommended Practices and Requirements for Harmonic Control in Electrical Power Systems, IEEE standards 5191992, April (1993).

[2] IEEE Recommended Practice and Requirements for Harmonic Control in Electric Power Systems, IEEE Std. 519-2014 (Revision of IEEE Std. 519-1992), March (2014).

[3] J. S. Subjak and J. S. Mcquilkin (1990) "Harmonics-Causes, effects, measurements, and analysis: An update," IEEE Transactions on Industry Applications, 26(6), 1034-1042.

[4] B. K. Bose (1992) "Recent advances in power electronics," IEEE Transactions on Power Electronics, 7(1), pp. 2-16.

[5] E. Kazemi-Robati, M.S.Sepasian (2019) "Passive harmonic filter planning considering daily load variations and distribution system reconfiguration" Electric Power Systems Research, 166, 125-135.
[6] D. Bose, S. Biswas, A.V. Vasilakos, S. Laha, (2014) Optimal filter design using an improved artificial bee colony algorithm, Elsevier, Information Sciences, 281 (10), 443-461.

[7] A.S.S.Murugan, S.P.Rajaram and P.Renukadevi (2016) "Harmonic reduction using optimized passive filter based on Dragonfly Algorithm (DA)" International conference on Emerging Trends in Electrical, Electronics and Communication Systems (ICEEECS'16), 24-26 September, 107-111.

[8] D.Maheswaran, N.Rajasekar, L.Ashok Kumar, (2014) "Design of Passive Filters for Reducing Harmonic Distortion and Correcting Power Factor in Two Pulse Rectifier Systems using Optimization" , Journal of Theoretical and Applied Information Technology, 62(3), 720728.

[9] Yaow-Ming Chen, (2003) "Passive filter design using genetic algorithms", IEEE Transactions on Industrial Electronics, 50(1), 202-207.

[10]X.S.Yang, "Nature-Inspired Algorithms and Applied Optimization", Springer International Publishing (2018).

[11]J.Kennedy and R.Eberhart, (1995) "Particle Swarm Optimization" IEEE ICNN'95 International Conference on Neural Networks, 1942-1948.

[12]T.Apostolopoulos and A.Vlachos (2011) "Application of the Firefly Algorithm for Solving the Economic Emissions Load Dispatch Problem", Hindawi Publishing Corporation, International Journal of Combinatorics, 1-23.

[13]N.F.Johari, A.M.Zain, N.H.Mustaffa and A.Udin (2013) "Firefly Algorithm for Optimization Problem", Applied Mechanics and Materials, 421, 512-517. 